\title{
Challenges in rehabilitation of patients with nontraumatic spinal cord dysfunction due to tumors
}

\section{A narrative review}

\author{
Anna Pataraia (D) $\cdot$ Richard Crevenna
}

Received: 21 January 2019 / Accepted: 25 June 2019 / Published online: 16 July 2019

(C) The Author(s) 2019

\begin{abstract}
Summary The incidence of cancer-associated nontraumatic spinal cord dysfunction is rising due to population aging and better cancer treatment. The overall benefit of rehabilitation in specialized facilities for traumatic spinal cord dysfunction has been confirmed many times. Because of their fragility and multiple comorbidities cancer patients still face challenges to complete rehabilitation in the spinal rehabilitation facilities. In this narrative review we describe specific aspects, challenges in rehabilitation and opportunities to improve care. A literature search was performed in the PubMed database from 1 January 1978 to 30 November 2018. The focus was to find publications that discuss challenges and opportunities for rehabilitation of patients with non-traumatic spinal cord dysfunction due to a tumor. Most publications described the benefits of rehabilitation in specialized facilities. There were only few publications about survival and functional outcomes after rehabilitation for this patient population. Overall benefits including fewer complications associated with spinal cord dysfunction, less pain and depression, and better quality of life were shown. Within the past decades increasing number of publications revealed a growing interest for this group of patients. Despite major progress in cancer treatment, patients still have a limited vital prognosis and access to specialized rehabilitation units because of the concerns about the medical complexity. Patients with spinal cord tumors can benefit in areas of functionality, mood, quality of life, and survival from inpatient rehabilitation programs, in spite of the increased medical comorbidities.
\end{abstract}

\footnotetext{
A. Pataraia $(\bowtie) \cdot R$. Crevenna

Department of Physical Medicine, Rehabilitation and

Occupational Medicine, Medical University of Vienna,

Währinger Gürtel 18-20, 1090 Vienna, Austria

anna.pataraia@meduniwien.ac.at
}

Keywords Spinal cord injury $\cdot$ Non-traumatic spinal cord dysfunction · Tumor · Rehabilitation · Barriers

\section{Introduction}

Spinal cord injury (SCI) is a debilitating condition resulting in paralysis with associated severe consequences. Non-traumatic spinal cord dysfunction (NTSCD) is suspected to be more common than a traumatic SCI in many developed countries, with best evidence shown in publications from Canada, Australia and Norway [1-3]. A wide range of heterogeneous etiologies cause NTSCD. The most common causes are degenerative changes of the spinal column, benign and malignant tumors, vascular diseases, infections and inflammation [4-6]. The patients with NTSCD are usually older, with a typical median age of 60-65 years [1, 4, 6]. Tumors account for up to one third of all NTSCD patients admitted into spinal cord rehabilitation units (SRU) $[4,5]$. With expected aging of the population in the near future the incidence of NTSCD due to tumors will also increase and potentially overwhelm healthcare services [7-9]. While most aspects of rehabilitation for traumatic spinal cord injury and NTSCD are the same, people with NTSCD due to a tumor have some unique rehabilitation issues when considering the functional deficits from the spinal cord involvement, comorbidity and life expectancy $[10,11]$. The primary goal of the rehabilitation of such patients is improvement of maximum functional independence, the quality of life and a reintegration into daily life [12]. It is not surprising that rehabilitation of the patients is a great challenge. It requires a multidisciplinary approach, which includes surgical, radiation and oncological treatment [13]. Considering that, a high percentage of patients with neoplastic spinal cord compression can be discharged to home [14]. Patients with NTSCD 
have a better outcome when the rehabilitation is carried out in spinal cord rehabilitation units compared to a general rehabilitation, since these units have the spinal cord medical rehabilitation expertise with improved access to vital services $[15,16]$. Although the early detection of tumors and advances in the oncological treatment has improved in the last decades, the full access to rehabilitative services still has barriers caused by the patient fragility and complications from concurrent medical treatment [17].

The early recognition of NTSCD with its associated neurological complications and timely submission to rehabilitation would result in better functional independence of the patients but the long-term results of rehabilitation are not depicted in newer studies. This primarily resulted from the poor survival time $[17,18]$. Despite the high proportion of people with a tumor causing NTSCD, there are relatively few publications about the conditions of the ideal rehabilitation setting and there is also a lack of recommendations for rehabilitation $[14,15]$. This narrative review tries to identify specific aspects and challenges in rehabilitation of patients with NTSCD due to tumors and the possibilities to improve rehabilitation.

\section{Methods}

The narrative review includes most relevant studies regarding the rehabilitation of patients with NTSCD due to tumors (both benign and malignant), which were published in the PubMed database. The search was conducted in November 2018, the search period was restricted to 1 January 1978 to 30 November 2018 and included the following keywords: spinal cord injury, spinal cord dysfunction, tumor and rehabilitation. After assessing the most relevant studies a search of secondary sources was performed, which also included the references of initially identified articles. Only literature published in the English language and involving humans was included. The focus of this search was to identify publications that discuss challenges and possibilities for rehabilitation of patients with NTSCD due to tumors.

\section{General rehabilitation issues}

There are numerous publications about the benefits of inpatient rehabilitation in SRU compared to general rehabilitation facilities [19, 20]. Despite that, many SRU preferentially admit SCI over those with NTSCD $[20,21]$. The important aspects for this are uncertain neurological prognosis and relatively short life expectancy. Patients with limited life expectancy are managed with shorter rehabilitation hospital admissions, which focus on basic rehabilitation goals and adaptation of temporary devices [20]. Predicting neurological improvement, rehabilitation outcomes, and survival is extremely challenging and there is very little literature on this aspect $[22,23]$. People with NTSCD due to tumors are generally older with more comorbidities, which can influence rehabilitation outcomes. Overall, persons with NTSCD benefit from inpatient rehabilitation [6, 20, 21, 24, 25].

\section{Oncological status and management}

The primary goal of cancer therapy is to maintain the neurological status, reduce pain and avoid further complications [29]. Management of spinal tumors varies depending on numerous factors, such as stability of the spine, pain quality and changes in neurological status [26]. It is influenced by different treatment procedures, which include surgery, radiation therapy, and concomitant chemotherapy. The surgery should be performed in patients with spinal instability with concomitant compression of the spinal cord. After complete removal of the tumor, the survival rates increase $[27,28]$. Myelopathy is a potential side effect of radiation therapy, which may appear early after treatment or with a delay of up to 2 years [31]. For some tumors, chemotherapy can also be used as an adjuvant therapy and corticosteroids are also often prescribed [32]. The side effects of corticosteroids, such as hyperglycemia, infections and impaired wound healing as well as gastrointestinal bleeding and mood disorder can have a devastating impact on the patient quality of life and the rehabilitation process [32].

\section{Secondary health conditions influencing rehabili- tation and their management}

Patients with NTSCD due to tumors experience neurological complications, such as pain, bowel and bladder dysfunction, pressure ulcers, increased skin fragility and sexual dysfunction. Some of these conditions may be further complicated due to the tumor and consequently have an influence on the rehabilitation process [33]. The most common complication of neoplastic spinal cord compression is pain [33-35] and could appear up to several months prior to neurological deficits [36]. The pain is the result of spinal cord compression, bony destruction, vertebral instability due to fast growth of the tumor or spinal nerve root compression [33]. Pain management should be adequate and pain relief can be achieved by strengthening of the body stability with different modalities, such as electrical stimulation, ultrasound and heat or cold treatment $[37,38]$. Medications including nonsteroidal anti-inflammatory drugs, anticonvulsants, tricyclic antidepressants, steroids, and opioids can also significantly reduce pain [39-41]. Another complication is constipation due to inadequate emptying of the bowels $[12,42]$. It can be caused due to the affection of motor neurons by the tumor and may be intensified by immobility and malnutrition. An active bowel evacuation should be quickly initiated and supported by stool softener medication and laxatives combined with digital stimulation [13]. Bladder 
dysfunction is another common delayed complication of NTSCD and may present as symptoms, such as urgency, retention or incontinence, and frequent urinary tract infections [12, 33]. Bladder management methods include timed voiding, intermittent catheterization, and indwelling catheters [33].

The skin of patients with NTSCD can be affected by developing pressure ulcers, which can be worsened due to immobility, bladder and bowel incontinence, and malnutrition. A large proportion of this complication is preventable using appropriate techniques and education of the patient and caregivers [12]. Patients who undergo radiation treatment can develop dermatitis, hair loss, atrophy and fibrosis of the skin with loss of pigmentation [43, 44]. Patients with NTSCD can experience sexual dysfunction. This may be as a result of spinal cord injury due to cancer but sometimes it also occurs after oncological treatment [45]. The rehabilitation program should include education of patients, using assistive devices and if necessary, oral medications for sexual dysfunction [46].

\section{Rehabilitation issues of patients with NTSCD}

Rehabilitation of patients with NTSCD due to tumors is compounded by several factors, including overall tumor burden with associated secondary depression, adverse reaction of different anti-tumor medications, sedative effect of pain relief medication, effect of radiation, and tumor-related fatigue. Some of these factors can be influenced by correction of the causes. For example, fatigue could be a result of anemia or hypothyroidism secondary to radiation. Thus, supportive care is essential and will help in optimization and improvement of the rehabilitation course [47]. Adequate pain treatment should be applied after cancer surgery. Although pain could also be secondary to neoplastic nerve/spinal cord compression and induced by radiation therapy or chemotherapy $[48,49]$. Cancer patients are more susceptible to both anorexia and cachexia [50]. Depressive disorders are prevalent in cancer patients and often remain undetected and untreated [51]. Respiratory complications, wound infection or dehiscence, bleeding, as well as cerebrospinal fluid leakage are some of the side effects of oncological treatment [30]. Infections are also common and could be due to neutropenia from chemotherapy or concurrent steroid use [52]. Patients with NTSCD frequently develop deep venous thromboembolism, despite receiving anticoagulation therapy [53]. Anemia in cancer patients is multifactorial and may be caused by chronic blood loss, iron deficiency, chemotherapy-induced myelosuppression and many other factors. Typically, anemia is treated with iron substitution, erythropoietic stimulating agents or transfusion [54].

When diagnosed with cancer and spinal cord dysfunction, patients have to undergo difficult adjustments, from denial of their disability to acceptance and learning to live with a new situation [55]. Patients' individual perception of quality of life is influenced by spiritual well-being and level of education, which should be taken into account when designing a rehabilitation program [56]. It is also important to discuss advance healthcare directives and resuscitation orders with the patients [57]. The oncological prognosis should be an essential factor for designing the goals of a rehabilitation program, even though inpatient rehabilitation has proven advantages in many aspects, such as improved survival and self-care [58]. Positive effects of rehabilitation have been shown in numerous publications [6, 20, 21, 24, 59, 60]. The majority of patients with NTSCD maintained even several months after discharge improvements in wheelchair use, ambulation, stair climbing, dressing and personal hygiene [33]. Fewer patients that completed inpatient rehabilitation programs were readmitted to the hospital as a result of medical complications [24]. Patients with less aggressive tumors who were treated with surgery and radiation and showed slowly progressing neurological symptoms and better ambulation prior to rehabilitation, had improved outcomes and survived longer with a better quality of life [59]. Patients with NTSCD due to a tumor should be assessed differently than the patients with traumatic SCI when the care support plan is being designed. Patients with cancer involvement for spinal cord dysfunction are generally older und multimorbid [61]. Rehabilitation programs for NTSCD and traumatic SCI patients are similar in many ways but some adjustments always have to be made based on concomitant cancer-related health disorders, for example fatigue or cachexia. It is also important to educate patients appropriately about bowel and bladder care, which contributes to prevention of additional skin damage and improves survival for several months $[62,63]$. Skin integrity may also be affected due to concurrent malnutrition and radiation effects, which could pose significant problems, such as prolonging the rehabilitation because of pre-existing pressure sores [58, 64].

\section{Setting of rehabilitation and practical considera- tions}

Authors of several studies have shown that patients with functional loss from spinal cord compression can make significant functional gains from inpatient rehabilitation from admission to discharge based on total functional independence measure scores [19-21, 60]. The majority of patients who underwent inpatient rehabilitation maintained self-care and mobility and achieved independent function 1 year after discharge [33, 62, 63]. Several studies could show that the ideal setting for rehabilitation for people with NTSCD due to tumors is a SRU $[19,24,58]$. A discussion regarding anticipated rehabilitation goals, estimated length of hospital stay, likely costs of the equipment, possible home modifications, and an estimate of ongoing 
care should be done. Criteria have been proposed for guiding decisions regarding the rehabilitation of people with NTSCD due to tumors and have been successfully implemented in SRUs $[11,65]$. Key aspects of these rehabilitation criteria are summarized as follows:

- Main attention should be paid to the neurological status and to the degree of spinal cord damage. With increased severity of spinal cord damage, the changes of improvements in neurological function are decreased.

- The next important step in choosing the rehabilitation unit is the determination of oncological status. Prognosis varies considerably for tumors of different types.

- Secondary medical health conditions can influence patient's ability to participate in rehabilitation and need to be optimally managed. Primarily a comprehensive evaluation and management of pain should be done.

- The patients' social support has a major influence on planning discharge to home and should be discussed from the very beginning of the rehabilitation.

These criteria are vital to guide the decision of admitting patients with NTSCD due to tumors into SRU [6, $65,66]$. Rehabilitation-specific team and organization issues include a target length of stay for inpatient rehabilitation, based on previous studies and opinion of experts, of 4-6 weeks for those with a poor prognosis $[33,58,64,65]$. A multidisciplinary approach with regular consultation meetings is required to determining the best treatment for a patient with NTSCD [67].

\section{Conclusion}

In the past decades, a growing interest for NTSCD is reflected in increased publication numbers for this group of patients. Despite major progress in cancer treatment, patients with NTSCD due to a tumor still have a limited vital prognosis and access to specialized rehabilitation units. Full access to treatment in SRUs is still limited due to concerns about fragility and medical complexity associated with this diagnosis. Patients with spinal cord tumors can benefit in areas of functionality, mood, quality of life, and survival from inpatient rehabilitation programs, in spite of increased medical comorbidity from the disease process itself.

Acknowledgements The authors thank Marine Dididze and Sopiko Jimsheleishvili for proofreading and editing the paper.

Funding Open access funding provided by Medical University of Vienna.

Conflict of interest A. Pataraia and R. Crevenna declare that they have no competing interests.

Open Access This article is distributed under the terms of the Creative Commons Attribution 4.0 International License (http://creativecommons.org/licenses/by/4.0/), which permits unrestricted use, distribution, and reproduction in any medium, provided you give appropriate credit to the original author(s) and the source, provide a link to the Creative Commons license, and indicate if changes were made.

\section{References}

1. NewPW,SundararajanV.Incidence ofnon-traumatic spinal cord injury in Victoria, Australia: A population-based study and literature review. Spinal Cord. 2008;46(6):406-11.

2. Noonan VK, Fingas M, Farry A, Baxter D, Singh A, Fehlings MG, et al. Incidence and prevalence of spinal cord injury in Canada: Anational perspective. Neuroepidemiology. 2012;38(4):219-26.

3. Halvorsen A, Pettersen AL, Nilsen SM, Halle KK, Schaanning EE, Rekand T. Non-traumatic spinal cord injury in Norway 2012-2016: Analysis from a national registry and comparison with traumatic spinal cord injury. Spinal Cord. 2019;57(4):324-30.

4. New PW, Cripps RA, Bonne Lee B. Global maps of nontraumatic spinal cord injury epidemiology: Towards aliving data repository. Spinal Cord. 2014;52(2):97-109.

5. New PW, Marshall R. International spinal cord injury data sets for non-traumatic spinal cord injury. Spinal Cord. 2014;52(2):123-32.

6. New PW, Reeves RK, Smith E, Eriks-Hoogland I, Gupta A, Scivoletto G, et al. International retrospective comparison of inpatient rehabilitation for patients with spinal cord dysfunction: Differences according to etiology. Arch Phys Med Rehabil. 2016;97(3):380-5.

7. Smith BD, Smith GL, Hurria A, Hortobagyi GN, Buchholz TA. Future of cancer incidence in the United States: Burdens upon an aging, changing nation. J Clin Oncol. 2009;27(17):2758-65.

8. Ge L, Arul K, Ikpeze T, Baldwin A, Nickels JL, Mesfin A. Traumatic and nontraumatic spinal cord injuries. World Neurosurg. 2018;111:e142-e8.

9. Ge L, Arul K, Mesfin A. Spinal cord injury from spinal tumors: Prevalence, management, and outcomes. World Neurosurg. 2019;122:e1551-e6.

10. RajVS, Lofton L. Rehabilitation and treatment of spinal cord tumors. JSpinal Cord Med. 2013;36(1):4-11.

11. Stubblefield MD, Bilsky MH. Barriers to rehabilitation of the neurosurgical spine cancer patient. J Surg Oncol. 2007;95(5):419-26.

12. Kirshblum S, O'Dell MW, Ho C, Barr K. Rehabilitation of persons with central nervous system tumors. Cancer. 2001;92(4 Suppl):1029-38.

13. Abrahm JL, Banffy MB, Harris MB. Spinal cord compression in patients with advanced metastatic cancer: "all I care about is walking and living my life". JAMA. 2008;299(8):937-46.

14. Guo Y, Young B, Palmer JL, Mun Y, Bruera E. Prognostic factors for survival in metastatic spinal cord compression: A retrospective study in a rehabilitation setting. Am J Phys Med Rehabil. 2003;82(9):665-8.

15. New PW. Non-traumatic spinal cord injury: What is the ideal setting for rehabilitation? Aust Health Rev. 2006;30(3):353-61.

16. Scivoletto G, Lapenna LM, Di Donna V, Laurenza L, Sterzi S, Foti C, et al. Neoplastic myelopathies and traumatic spinal cord lesions: An Italian comparison of functional and neurological outcomes. Spinal Cord. 2011;49(7):799-805. 
17. Palacio A, Calmels P, Genty M, Le-Quang B, Beuret-BlanquartF. Oncology and physicalmedicineand rehabilitation. Ann Phys Rehabil Med. 2009;52(7/8):568-78.

18. Scivoletto G, Farchi S, Laurenza L, Molinari M. Traumatic and non-traumatic spinal cord lesions: An Italian comparison of neurological and functional outcomes. Spinal Cord. 2011;49(3):391-6.

19. Tan M, New PW. Retrospective study of rehabilitation outcomes following spinal cord injury due to tumour. Spinal Cord. 2012;50(2):127-31.

20. New PW, Simmonds F, Stevermuer T. Comparison of patients managed in specialised spinal rehabilitation units with thosemanaged in non-specialised rehabilitation units. Spinal Cord. 2011;49(8):909-16.

21. Fortin CD, Voth J, Jaglal SB, Craven BC. Inpatient rehabilitation outcomes in patients with malignant spinal cord compression compared to other non-traumatic spinal cord injury: A population based study. J Spinal Cord Med. 2015;38(6):754-64.

22. Nater A, Tetreault LL, Davis AM, Sahgal AA, Kulkarni AV, Fehlings MG. Key preoperative clinical factors predicting outcome in surgically treated patients with metastatic epidural spinal cord compression: Results from a survey of 438 AOSpine international members. World Neurosurg. 2016;93:436-448.e15.

23. Choi D, Pavlou M, Omar R, Arts M, Balabaud L, Buchowski JM, et al. A novel risk calculator to predict outcome after surgery for symptomatic spinal metastases; use of a large prospective patient database to personalise surgical management. Eur JCancer. 2018;107:28-36.

24. Eriks IE, Angenot EL, Lankhorst GJ. Epidural metastatic spinal cord compression: Functional outcome and survival after inpatient rehabilitation. Spinal Cord. 2004;42(4):235-9.

25. Alam E, Wilson RD, Vargo MM. Inpatient cancer rehabilitation: A retrospective comparison of transfer back to acute care between patients with neoplasm and other rehabilitation patients. Arch Phys Med Rehabil. 2008;89(7):1284-9.

26. Wetzel FT, Phillips FM. Management of metastatic disease of the spine. Orthop Clin North Am. 2000;31(4):611-21.

27. Rades D, Karstens JH. A comparison of two different radiation schedules for metastatic spinal cord compression considering a new prognostic factor. Strahlenther Onkol. 2002;178(10):556-61.

28. Sundaresan N, Sachdev VP, Holland JF, Moore F, Sung M, Paciucci PA, et al. Surgical treatment of spinal cord compression from epidural metastasis. J Clin Oncol. 1995;13(9):2330-5.

29. RompeJD, HopfCG, Eysel P. Outcome after palliative posterior surgery for metastatic disease of the spine-Evaluation of 106 consecutive patients after decompression and stabilisation with the Cotrel-Dubousset instrumentation. Arch Orthop Trauma Surg. 1999;119(7/8):394-400.

30. Kim JM, Losina E, Bono CM, Schoenfeld AJ, Collins JE, Katz JN, et al. Clinical outcome of metastatic spinal cord compression treated with surgical excision $+/$ - radiation versus radiation therapy alone: A systematic review of literature. Spine. 2012;37(1):78-84.

31. Rampling R, Symonds P. Radiation myelopathy. Curr Opin Neurol. 1998;11(6):627-32.

32. Drudge-Coates L, Rajbabu K. Diagnosis and management of malignant spinal cord compression: Part 2. Int J Palliat Nurs. 2008;14(4):175-80.

33. McKinley WO, Conti-Wyneken AR, Vokac CW, Cifu DX. Rehabilitative functional outcome of patients with neoplastic spinal cord compressions. Arch Phys Med Rehabil. 1996;77(9):892-5.
34. Foley KM. The treatment of pain in the patient with cancer. CACancer JClin. 1986;36(4):194-215.

35. Collins JJ, Grier HE, Kinney HC, Berde CB. Control of severe pain in children with terminal malignancy. J Pediatr. 1995;126(4):653-7.

36. Helweg-Larsen S, Sorensen PS. Symptoms and signs in metastatic spinal cord compression: A study of progression from first symptom until diagnosis in 153 patients. Eur J Cancer. 1994;30(3):396-8.

37. Filshie J. The non-drug treatment of neuralgic and neuropathic pain of malignancy. Cancer Surv. 1988;7(1):161-93.

38. Mayer DK. Non-pharmacologic management of pain in the person with cancer. JAdv Nurs. 1985;10(4):325-30.

39. Jadad AR, Browman GP. The WHO analgesic ladder for cancer pain management. Stepping up the quality of its evaluation. JAMA. 1995;274(23):1870-3.

40. Dworkin RH, O'Connor AB, Backonja M, Farrar JT, Finnerup NB, Jensen TS, et al. Pharmacologic management of neuropathic pain: Evidence-based recommendations. Pain. 2007;132(3):237-51.

41. DeerTR, PopeJE, HayekSM, BuxA, BuchserE, EldabeS, etal. The Polyanalgesic Consensus Conference (PACC): Recommendations on Intrathecal druginfusion systems best practices and guidelines. Neuromodulation. 2017;20(2):96-132.

42. Stiens SA, Bergman SB, Goetz LL. Neurogenic bowel dysfunction after spinal cord injury: Clinical evaluation and rehabilitative management. Arch Phys Med Rehabil. 1997;78(3 Suppl):S86-S102.

43. Balagula Y, Rosen ST, Lacouture ME. The emergence of supportive oncodermatology: The study of dermatologic adverse events to cancer therapies. J Am Acad Dermatol. 2011;65(3):624-35.

44. BerkeyFJ.Managing theadverse effects of radiation therapy. AmFam Physician. 2010;82(4):381-8.394.

45. Pelusi J. Sexuality and body image. Cancer Nurs. 2006;29(2 Suppl):32-8.

46. Consortium for Spinal Cord Medicine. Sexuality and reproductive health in adults with spinal cord injury: A clinical practice guideline for health-care professionals. JSpinal Cord Med. 2010;33(3):281-336.

47. Klastersky J. From best supportive care to early palliative care. Curr Opin Oncol. 2011;23(4):311-2.

48. Marmiroli P, Scuteri A, Cornblath DR, Cavaletti G. Pain in chemotherapy-induced peripheral neurotoxicity. J Peripher Nerv Syst. 2017;22(3):156-61.

49. Delanian S, Lefaix JL, Pradat PF. Radiation-induced neuropathy in cancer survivors. Radiother Oncol. 2012;105(3):273-82.

50. Arthur ST, Van Doren BA, Roy D, Noone JM, Zacherle E, Blanchette CM. Cachexia among US cancer patients. J Med Econ. 2016;19(9):874-80.

51. Caruso R, GiuliaNanni M, Riba MB, Sabato S, Grassi L. Depressive spectrum disorders in cancer: Diagnosticissues and intervention. A critical review. Curr Psychiatry Rep. 2017;19(6):33.

52. Freifeld A, Sankaranarayanan J, Ullrich F, Sun J. Clinical practice patterns of managing low-risk adult febrile neutropenia during cancer chemotherapy in the USA. Support Care Cancer. 2008;16(2):181-91.

53. Deitcher SR. Cancer-related deep venous thrombosis: Clinical importance, treatment challenges, and management strategies. Semin Thromb Hemost. 2003;29(3):247-58.

54. Gilreath JA, Stenehjem DD, Rodgers GM. Diagnosis and treatment of cancer-related anemia. Am J Hematol. 2014;89(2):203-12. 
55. Eva G, Paley J, Miller M, Wee B. Patients' constructions of disability in metastatic spinal cord compression. Palliat Med. 2009;23(2):132-40.

56. Tate DG, Forchheimer M. Quality of life, life satisfaction, and spirituality: Comparing outcomes between rehabilitation and cancer patients. Am J Phys Med Rehabil. 2002;81(6):400-10.

57. Guo Y, Palmer JL, Bianty J, Konzen B, Shin K, Bruera E. Advance directives and do-not-resuscitate orders in patients with cancer with metastatic spinal cord compression: Advanced care planning implications. J Palliat Med. 2010;13(5):513-7.

58. Fattal C, Fabbro M, Rouays-Mabit H, Verollet C, Bauchet L. Metastatic paraplegia and functional outcomes: Perspectives and limitations for rehabilitation care. Part 2. Arch Phys Med Rehabil. 2011;92(1):134-45.

59. Hacking HG, Van As HH, Lankhorst GJ. Factors related to the outcome of inpatient rehabilitation in patients with neoplastic epidural spinal cord compression. Paraplegia. 1993;31(6):367-74.

60. McKinley WO, Seel RT, Gadi RK, Tewksbury MA. Nontraumatic vs. traumatic spinal cord injury: A rehabilitation outcome comparison. Am J Phys Med Rehabil. 2001;80(9):693-9. quiz 700, 716.

61. McKinley WO, Seel RT, Hardman JT. Nontraumatic spinal cord injury: Incidence, epidemiology, and functional outcome. Arch Phys Med Rehabil. 1999;80(6):619-23.
62. Murray PK. Functional outcome and survival in spinal cord injury secondary to neoplasia. Cancer. 1985;55(1):197-201.

63. Ruff RL, Ruff SS, Wang X. Persistent benefits of rehabilitation on pain and life quality for nonambulatory patients with spinal epidural metastasis. J Rehabil Res Dev. 2007;44(2):271-8.

64. Parsch D, Mikut R, Abel R. Postacute management of patients with spinal cord injury due to metastatic tumour disease: Survival and efficacy of rehabilitation. Spinal Cord. 2003;41(4):205-10.

65. New PW, Marshall R, Stubblefield MD, Scivoletto G. Rehabilitation of people with spinal cord damage due to tumor: Literature review, international survey and practical recommendations for optimizing their rehabilitation. J Spinal Cord Med. 2017;40(2):213-21.

66. New PW, Eriks-Hoogland I, Scivoletto G, Reeves RK, Townson A, Marshall R, et al. Important clinical rehabilitation principles unique to people with non-traumatic spinal cord dysfunction. Top Spinal Cord Inj Rehabil. 2017;23(4):299-312.

67. Ottevanger N, Hilbink M, Weenk M, Janssen R, Vrijmoeth T, de Vries A, et al. Oncologic multidisciplinary team meetings: Evaluation of quality criteria. J Eval Clin Pract. 2013;19(6):1035-43.

Publisher's Note Springer Nature remains neutral with regard to jurisdictional claims in published maps and institutional affiliations. 